\section{REPORT OF A CASE \\ OF}

\section{LATERAL TRANSPOSITION OF THE HEART AND LIVER IN A SOLDIER.}

BY W. C. MACLEAN, M.D., Dep. Insp.-General ; PROFESSOR OF MIIITARY MBDICINE, ARMY MRDICAL SCHOOL.

Private Isaiah A-, aged twenty-five; 106th Regt.; service three years and four months. The greater part of this man's brief service was spent in India, where he had been quartered at Bombay, Poonah, and Neemuch. His medical history sheet showed that he had been repeatedly in hospital for intermittent fever. He was admitted into the Royal Victoria Hospital, Netley, on the 20th of May, 1863, with all the physical signs of tubercular deposit in both lungs, and for this disability he was found unfit for further military duty and discharged the service.

During his stay in hospital the following peculiarities in the position of the heart and liver were noticed :-

Percussion in the normal precordial region elicited a sound abnormal in that situation. On further examination, the apex of the heart was observed to strike the thoracic wall on the right side between the sixth and seventh ribs, in a line one inch internal to the right nipple. Percussion elicited a dull sound over a space extending from above downwards from the fourth rib to midway between the sixth and seventh ribs, and laterally from the centre of the sternum to a line running one inch internal to the right nipple. The cardiac sounds were quite distinct in the region above defined, and quite normal in rhythm and intensity. There was no empyema on the left side to cause this displacement of the heart. Carrying on the examination, it was discovered that the liver was placed in the left hypochondriac and epigastric regions; dulness extended over a space bounded superiorly by the eighth rib, and inferiorly by a line corresponding to the margins of the false ribs on that side. On percussing the right hypochondriac region, tympanitic resonance was elicited; immediately after taking food the percussion note in this region became dull. Notwith. standing the repeated attacks of intermittent fever from which the man had suffered, the spleen was not enlareed, and percussion did not show any change in the position of this organ. The umbilicus was peculiar, its direction being frrm left to right. The right testicle was suspended on a lower level than the left, and the man was left-handed. The accompanying engraving shows the above peculiarities in the disposition of the organs, the dark lines denoting the regions of abnormal dulness.

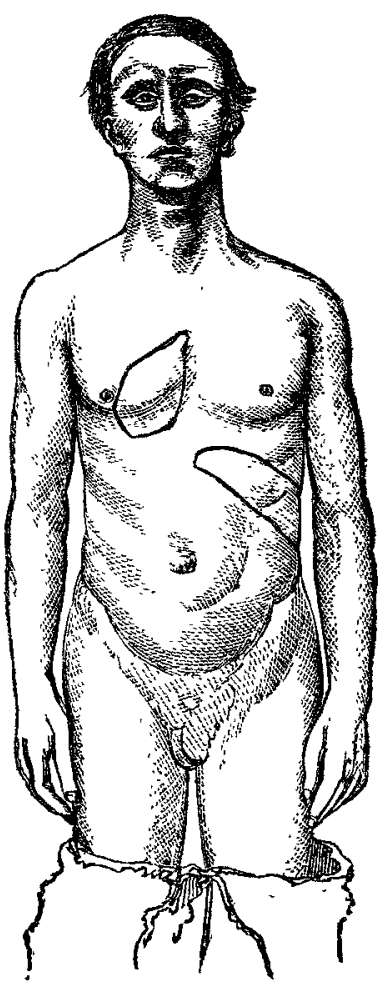

The patient was himself aware of the irregular position of his heart. Like many delicate soldiers, he was liable to attacks of palpitation at drill, when the free movements of his chest were interfered with by the pressure of his tight tunic and accoutrements; at such times he observed that his "heart beat on his right side," and he had often pointed out the transposition to his comrades. For obvious reasons he never suspected the irregular position of his liver. There is no reason to suppose that this transposition of organs exerted any injurious influence on their functions.

Professor Allen Thomson, in the Glasgow Medical Journal for July, 1853, published a notice of the dissection of a case of "Lateral Transposition of the Viscera of the Thorax and Abdomen in a Man." Professor Thomson in this paper shows, from his own observations and those of Professor Von Baer of Konigsberg, that this kind of malformation or transposition admits of a certain amount of elucidation from the consideration of embryological development; and to his paper I refer such of my readers as take an interest in inquiries of this nature.

Royal Victoria Hospital, Netley, July, 1863.

\section{DESCRIPTION OF A LARYNGOSCOPE.}

By FRANCIS MASON, Esq., F.R.C.S. (Exam.), ASSISTANT-SURGEON TO KING'S COLLEGE HOSPITAT.

The laryngoscope is becoming so generally adopted by the profession, that no doubt can exist of its value as an important aid in the diagnosis, and, consequently, in the treatment of disease. Notwithstanding what has been written regarding the examination of the vocal cords, epiglottis, and other appendages of the larynx, we have been scantily supplied with descriptions of the various instruments employed, and of the mode of their application.

The laryngoscope being, as its name implies, an arrangement for "looking at the larynx," the simplest apparatus by which this end may be attained is that which will be most readily received by all observers.

The subjoined woodcut represents an instrument made for me by Mr. Matthews, of Portugal-street. It is, in most respects, similar to that described by Dr. George Johnson elsewhere, and which he has done me the favour of showing me. The essential point of difference, however, is that the mirror, instead of working on a hook bent at an angle, is attached to the forehead-pad by means of a ball and socket joint. The universal movement thus afforded enables the surgeon to direct the rays of light with the greatest accuracy, and, by allowing him to assume a posture most easy to himself, to make a prolonged examination without fatigue.

The apparatus consists of a slightly concave mirror, three inches and $a$ half in diameter, having no central aperture. To the centre of the back of this $(a)$ is attached an accurately. fitting ball and socket joint $(b)$, provided with a screw to tighten the joint, should this proceeding be necessary. A stem, continued from the ball in front, is fixed to the forehead-pad (c), and from the extremities of the forehead-pad is fastened an elastic band, which encircles the head. Three or four laryngeal mirrors, varying in size, of the shape $(e)$, and set at the angle $(f)$, indicated in the engraving, complete the instrument. Each mirror tits the handle $(g)$. (Figs. $e, f, g$ are drawn exact size; the forehead mirror is reduced.)

The mode of examining the vocal cords is, in most cases, simple enough, and may be thus briefly described. The patient being seated on a firm chair, a lamp giving a brilliant and steady light is placed on one side of, and a little behind him. The surgeon, sitting opposite, fixes the mirror on the centre of his own forehead, and desiring the patient to advance his head slightly, directs the rays of light through the mouth to the back of the pharynx. The laryngeal mirror, having been previously warmed to prevent its becoming steamed by the breath, is now passed rapidly over the tongue, and made gently to elevate the soft palate. It should be borne in mind that the objects, as seen in the mirror, are reversed from before backwards. The base of the tongue, perhaps, will be first observed; next will be seen the epiglottis; and then, with careful manipulation, assisted by the patient saying the word "Ah!" the vocal apparatus may be demonstrated. In some cases it will be necessary to hold the tongue forward with a towel; this proceeding, how. ever, greatly distresses certain patients, the examination of whose throats may be better made either by depressing the F 2 
tongue with a common spatula, or by requesting them to retract and bury this organ, so to speak, in the floor of the mouth. Should the sunlight be employed to illumine the larynx, the laryngeal mirror will, of course, be the only instrument required.

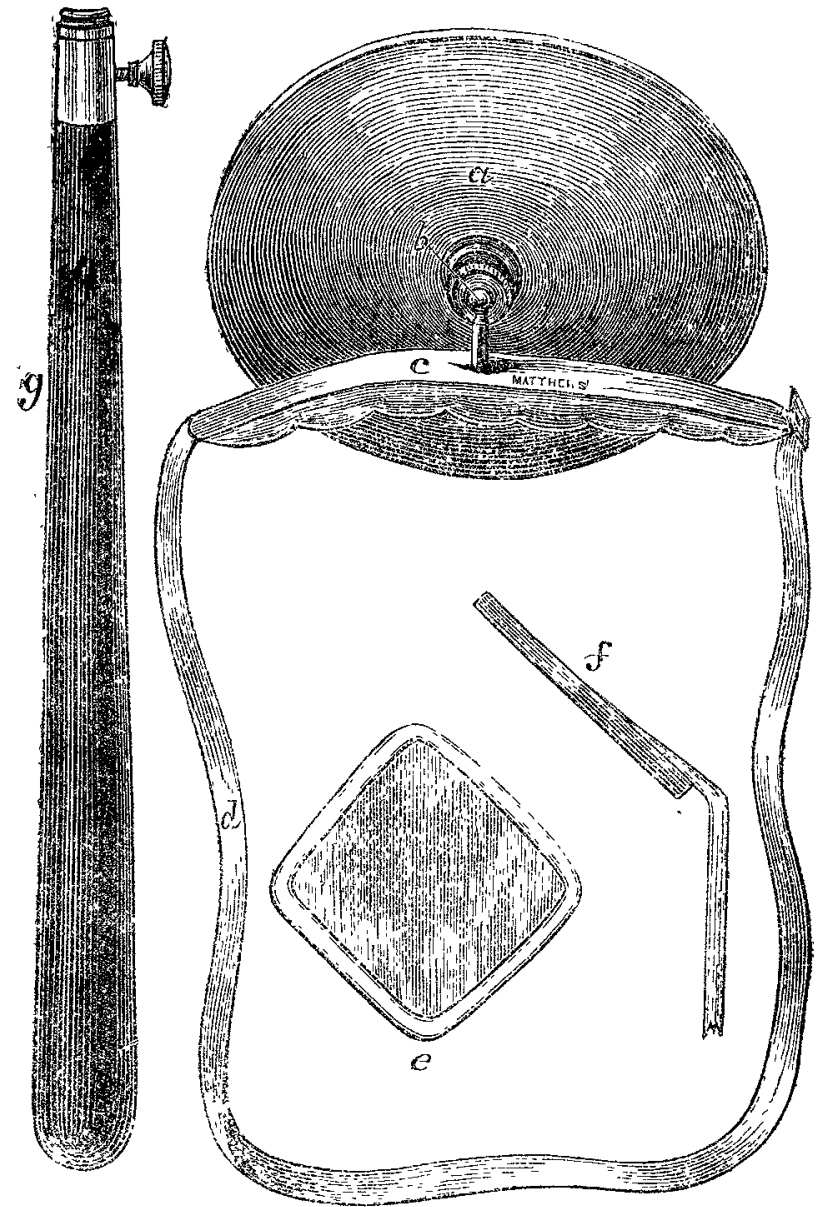

Thanks to the labours of Dr. Gibb much has already been done in this country to prove the value of the laryngoscope in the investigation of the physiological as well as the pathological condition of the air-passages, and much more remains yet to be accomplished. By moderate practice, however, anyone may make himself familiar with the instrument, and by properly. directed treatment in disease, alleviate much suffering and annoyance, which may have lasted for months, or even years.

Conduit-street, Regent-street, July, 1863.

ON A CASE
OF
EFFUSION AND LUMBAR
COMMUNICATING WITH
THE KIDNEY,

WHICH THE SPLEEN WAS EXCESSIVELY SMALL.

BY PHILIP W. JONES, L.E.C.P. Lond.

Susan C-, aged thirty-eight, tall, pasty complexion, with dark hair and eyes, was admitted into the West Riding Aylum, Wakefield, on the 2nd of July, 1862. The week after her admission she was employed in the kitchen, and continued so until the 2nd of September, when, lifting one of the large pan lids, she hurt her back; or, to use her own words, "she sprained her back." She fainted. An hour after the occurrence she was placed in bed, and complained of pain in the left lumbar region; there was great tenderness on pressure, and the lower half of the chest was dull. Ordered to be kept in bed.

Sept. 3rd. - She suffers less pain.

A few days afterwards she became excited, and continued so for three weeks; and, at her request, she went to the laundry, stating she was quite strong again, and was employed, daily, until the 20 th of November, when I was informed by the attendant that she had not taken her food so well as usual, which might be accounted for by the diarrhœa which she was then suffering from. With some hesitation she told me she was still suffering from pain in the left side and lumbar region, and that during the last few days it had been worse. The tongue was moist and flabby. She was put to bed, and on examining her chest $I$ found the dulness existing. Close to the eleventh and twelfth vertebræ there was a slight elevation with fluctua. tion, but not attended with any discoloration of the integument. She was ordered to be kept quiet and placed on extra diet, and the swelling to be painted with compound tincture of iodine. The next day she fancied herself better, but the swelling con. tinued to increase in size until the 2 nd of December, when she complained of dyspnoea; it was then deemed advisable to tap it by means of a trocar. Three ounces of ill-conditioned pus was drawn off; she fainted. In the evening her breathing was greatly relieved, and her countenance looked much more cheerful. During the night she was restless, and removed the bandage and plaster which had been put on after the tapping, allowing several ounces more of pus to escape. The following day she refused food, and there was a slight return of diarrboa; pulse feeble, and great thirst. Ordered brandy and a mixture containing opium; she passed a restless night, and appeared much worse the next morning. This condition gradually in. creased in severity, and she died during the following night.

Post-mortem examination. - The left side of the chest was filled with fluid of a straw colour, and, in consequence, the lung was compressed. On examining the abdomen a large abscess was found, the walls of which were adberent to the upper part of the left kidney, under surface of the stomach, and descending colon, which extended upwards on the psoas muscle, but beneath the pleura and diaphragm, and outwards between the eleventh and twelf $\mathrm{h}$ ribs. On making a section of left kidney, in the upper portion was seen a large cavity containing tubercle and pus, and communicating with the abscess; in the lower portion there was some slight deposit of tubercle. The spleen was excessively swall, measuring one inch in length, and weighing only two drachms.

Wakefeld, July, 1863 .

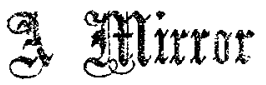

OF THE PRACTICE OF

\section{MEDICINE AND SURGERY IN THE}

\section{HOSPITALS OF LONDON.} Nulla autem est alia pro certo noscendi via, nisi quamplurimas et morborum,
ef dissectionum historias, tum aliorum, tum proprias collectas habere, et inter se comparare.-Horgagni De Sed. et Caus. ZIorb, lib.iv. Promium.

\section{WESTMINSTER HOSPITAL.}

EXTENSIVE PYOPERICARDIUM AND EMPYEMA; TAPPING OF THE LATTER TWICE; FATAL RESULT.

(Under the care of Dr. RaDchIFFE.)

THE following cases are recorded chiefly on account of the effusion of pus and blood into the pericardium. In the first there was empyema associated with the pericardial effusion, but the symptoms of the latter were obscure, and necessarily somewhat masked by the former. The sac was distended to its utmost, and formed a projecting bag the moment the chest was opened, as in Dr. Wilks's patient. It is a curious fact, that in some of these cases of effusion within the pericardium the amount of distress is not at all proportionate to the extent of the fluid; and cases have been recorded wherein as much as a gallon of pus occupied the interior of the mem. brane, whilst there was not the slightest appearance of impeded cardiac action.

For the abstract of the notes of the following case we are indebted to Mr. Gandy, house-physician to the hospital :-

Thos. $\mathrm{B}-$ aged twenty-eight, stonemason, was admitted Feb. 22nd, 1862. He caught cold a week or ten days previously. On the morning of the 21 st he, for the first time, experienced a sharp stabbing pain in the left side, aggravated in intensity 